\title{
USEFULNESS OF TECHNETIUM-99M-METH-
}

\author{
OXYISOBUTYLISONITRILE IMAGING
}

\section{AND INTRAOPERATIVE STAINING TECHNIQUE USING METHYLENE BLUE FOR LOCALIZATION : TWO CASES OF HYPERFUNCTIONING PARATHYROID LESIONS}

\author{
Yoshio Horii, Yuichi Inno*, Michio Maemura, \\ Hiroyuki Takei, Jun Horiguchi, Yukio Koibuchi, \\ Takao Yokoe*, Noboru Oriuchi**, Tomio Inoue**, \\ Keigo Endo**, Tsunehiro Ishida***, Yasuo Morishita \\ Second Department of Surgery, \\ *Department of Emergency and Critical Care Medicine, and \\ **Department of Nuclear Medicine, Gunma University School of Medicine, Maebashi, Japan \\ ${ }^{* * *}$ Department of Surgery, Takasaki National Hospital, Takasaki, Japan
}

\begin{abstract}
Two patients with primary hyperparathyroidism in whom it was difficult to search the location of abnormal parathyroid tissues are presented. Both patients, 35-year-old woman and 49-yearold man, had experienced several episodes of urolithiasis. A right lower (the former case) or right upper (the latter) parathyroid tumor was suspected by ultrasonography, but ${ }^{201} \mathrm{Tl}-\mathrm{Cl}$ and ${ }^{99 \mathrm{~m}} \mathrm{Tc}$-pertechnetate subtraction scintigraphy (TTSS) demonstrated no abnormal accumulation in the thyroid bed or mediastinum. At operation, no abnormal parathyroid gland was found in both patients. ${ }^{99 m} \mathrm{Tc}$ methoxyisobutylisonitrile scintigraphy revealed the presence of elusive parathyroid lesion in the mediastinum or at the lower position of the left thyroid lobe. At reoperation, intraoperative staining with methylene blue was useful to find out the lesions in both patients. The histological diagnosis was hyperplasia of the parathyroid in both. The normal calcium level was obtained promptly after the removal of these tissues.
\end{abstract}

Key words: ${ }^{99 m}$ Tc-MIBI, Hyperparathyroidism, Methylene blue staining, Ectopic parathyroid gland, Preoperative localization

(Kitakanto Med.J. 48 (5) : 367 371, 1998)

\section{INTRODUCTION}

For searching preoperative localization of a parathyroid tumor, ultrasonography (US), computed tomography $(\mathrm{CT})$, and thallium-201 chloride $\left({ }^{201} \mathrm{Tl}-\mathrm{Cl}\right)$ and technetium- $99 \mathrm{~m}$ pertechnetate $\left({ }^{99 \mathrm{~m}} \mathrm{TcO}_{4}{ }^{-}\right)$subtraction scintigraphy (TTSS) are useful. However, these exami- nations are sometimes of no use, especially for a small or an ectopic hyperfunctioning lesion. A new parathyroid imaging agent, technetium- $99 \mathrm{~m}$-methoxyisobutylisonitrile ( $\left.{ }^{99 \mathrm{~m}} \mathrm{Tc}-\mathrm{MIBI}\right)$, has been recently reported to be useful for such cases. We report two patients with elusive hyperfunctioning parathyroid lesions, whose localizations were detected by preoperative ${ }^{99 \mathrm{~m}} \mathrm{Tc}$-MIBI 

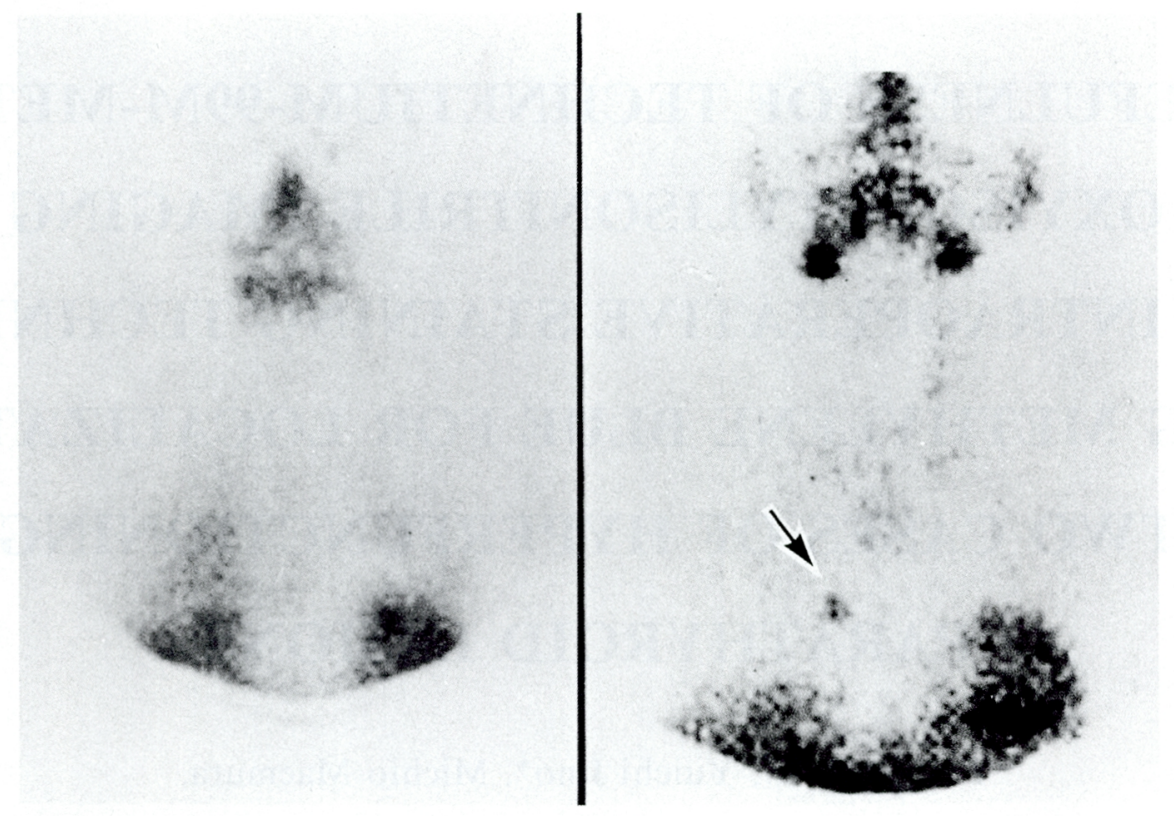

Fig.1 Case 1. ${ }^{201} \mathrm{Tl}-\mathrm{Cl}$ and ${ }^{99 m} \mathrm{TcO}_{4}{ }^{-}$subtraction scintigraphy demonstrated no abnormal accumulation in the thyroid region and mediastinum (left). ${ }^{99 m} \mathrm{Tc}-\mathrm{MIBI}$ and ${ }^{123} \mathrm{I}$ subtraction scintigraphy showed an increased accumulation (arrow) in the mediastinum (right). The right thyroid lobe had been resected at the first cervical exploration.

imaging and by intraoperative staining with methylene blue.

\section{CASE REPORTS}

\section{Case 1}

A 35-year-old woman diagnosed as primary hyperparathyrodism was introduced to our hospital in October, 1990. She had experienced several episodes of urolithiasis since she was 23 years old. A right lower parathyroid tumor was suspected by US and CT scan, whereas TTSS demonstrated no abnormal accumulation in the thyroid region and mediastinum (Fig.1). At intraoperative cervical exploration, no abnormal parathyroid gland was found on both sides. A part of the right thyroid lobe including fatty tissues was resected. However, only one normal parathyroid gland was histologically identified in the specimen. The patient had had a persistent hyperparathyroidism. In spite of various examinations including US, CT scan, magnetic resonance imaging (MRI), and TTSS, we failed to localize the pathological parathyroid gland. The patient had been followed up and received symptomatic treatments. In June, 1994, ${ }^{99 m}$ Tc-MIBI imaging revealed the presence of a tumor in the mediastinum (Fig.1). A thin slice CT scan of the chest was reexamined and a small nodular lesion was noted at the right side of the right atrial appendage. At the time of reoperation, $5 \mathrm{mg} / \mathrm{kg}$ body weight of methylene blue diluted in $200 \mathrm{ml}$ solution was intravenously adminis-

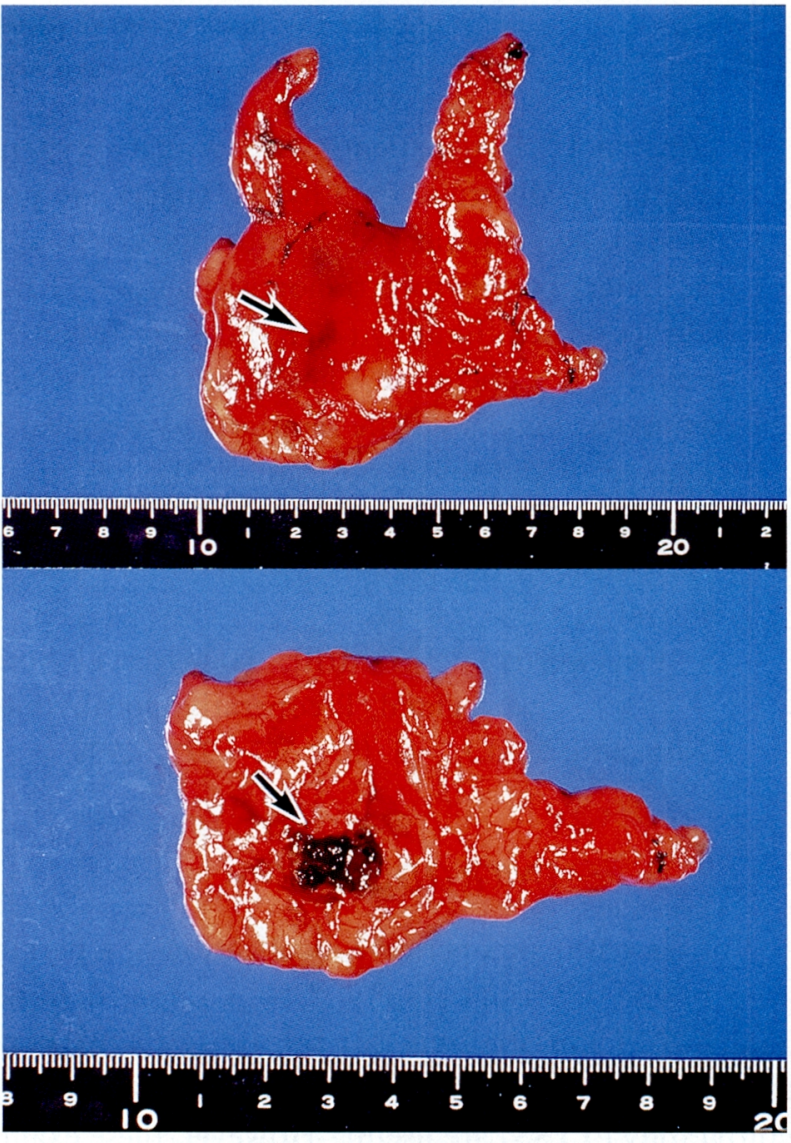

Fig.2 Case 1. Surgical specimen. A blue-stained nodule, 1.6 $\times$ $1.2 \times 0.8 \mathrm{~cm}$ in size, was seen in the right lobe of the thymus (arrow). 

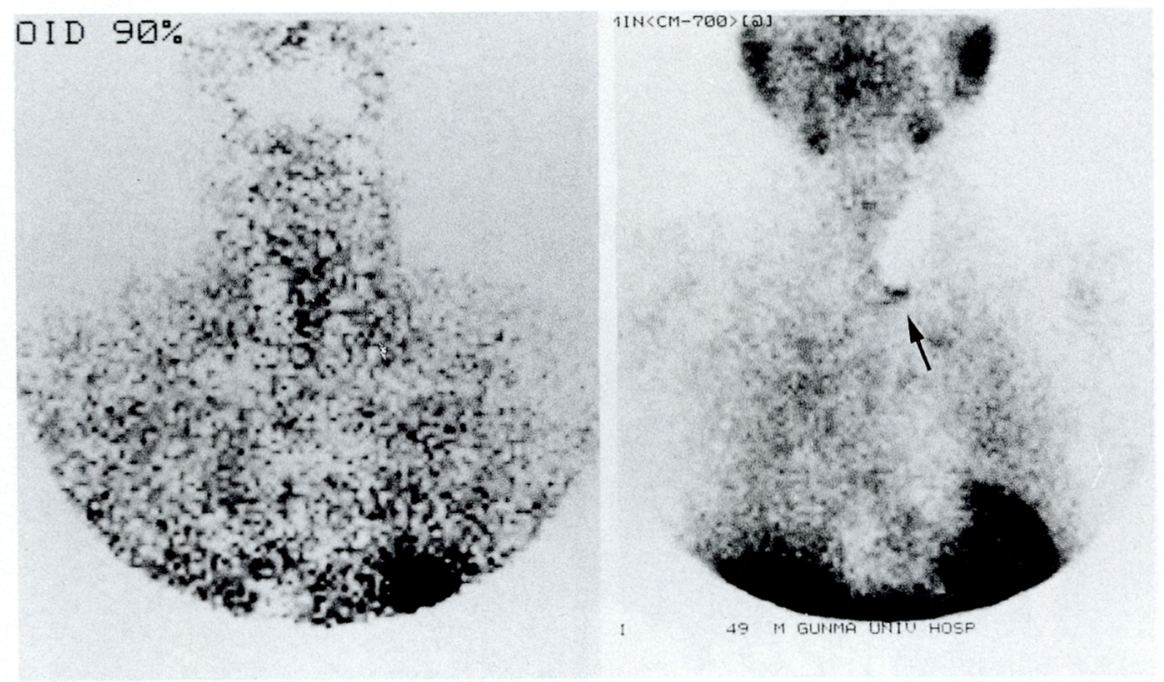

Fig.3 Case 2. ${ }^{201} \mathrm{Tl}-\mathrm{Cl}$ and ${ }^{99 \mathrm{~m}} \mathrm{TcO}_{4}{ }^{-}$subtraction scintigraphy. No abnormal accumulation was seen in the thyroid region and mediastinum (left). ${ }^{99 \mathrm{~m}} \mathrm{Tc}-\mathrm{MIBI}$ and ${ }^{123}$ I subtraction scintigraphy showed an increased accumulation (arrow) at the lower position of the left thyloid lobe (right). The right thyroid lobe had been resected at the first cervical exploration.

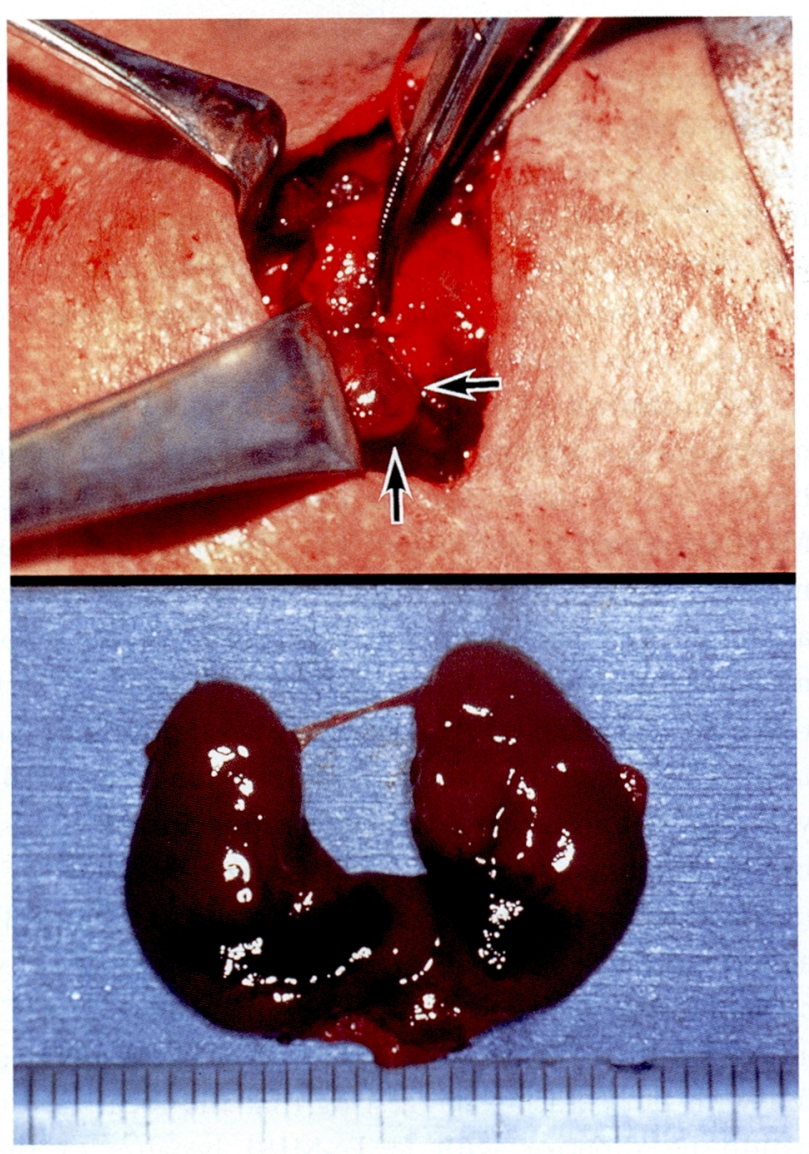

Fig.4 Case 2. Local appearance at the second cervical exploration (top). The left inferior parathyloid gland (arrow) stained to be blue. Surgical specimen (bottom; cut surface). A blue-stained gland measuring $1.4 \times 0.9 \times 0.5 \mathrm{~cm}$.

tered with taking 30 to 60 minutes. Following a median sternotomy, a blue-stained nodule was identified in the right lobe of the thymus, which was resected. A solid mass, $1.6 \times 1.2 \times 0.8 \mathrm{~cm}$ in size, was found in the resected specimen (Fig.2). The histological diagnosis was hyperplasia of the parathyroid. The normal calcium level was obtained promptly after the removal of the tumor.

\section{Case 2}

A 49-year-old man with the diagnosis of primary hyperparathyrodism was introduced to our hospital in August, 1993. He had experienced several episodes of urolithiasis. A right upper parathyroid tumor was suspected by US. TTSS demonstrated no abnormal accumulation in the thyroid region and mediastinum (Fig.3). At operation, the parathyroid gland was not swelling. The right thyroid lobe including two right parathyroid glands and the left superior parathyloid gland were resected. No pathologic parathyroid gland was histologically identified in the resected specimen. Hyperparathyroidism still persisted after surgery. US, MRI, or whole body thallium scan failed to localize the remaining or ectopic parathyroid gland. After receiving symptomatic therapy for a while, ${ }^{99 \mathrm{~m}} \mathrm{Tc}-\mathrm{MIBI}$ imaging performed in June, 1994 demonstrated the presence of a tumor at the lower position of the left thyroid lobe (Fig.3). A thin slice CT scan of the neck was reexamined, but no nodular lesion was identified. At a second cervical exploration in Takasaki National Hospital in February, 1995, intraoperative methylene blue staining was employed in the same way as case 1 . A blue-stained nodule was identified at the left side of the esophagus, and was excised. The specimen mea- 


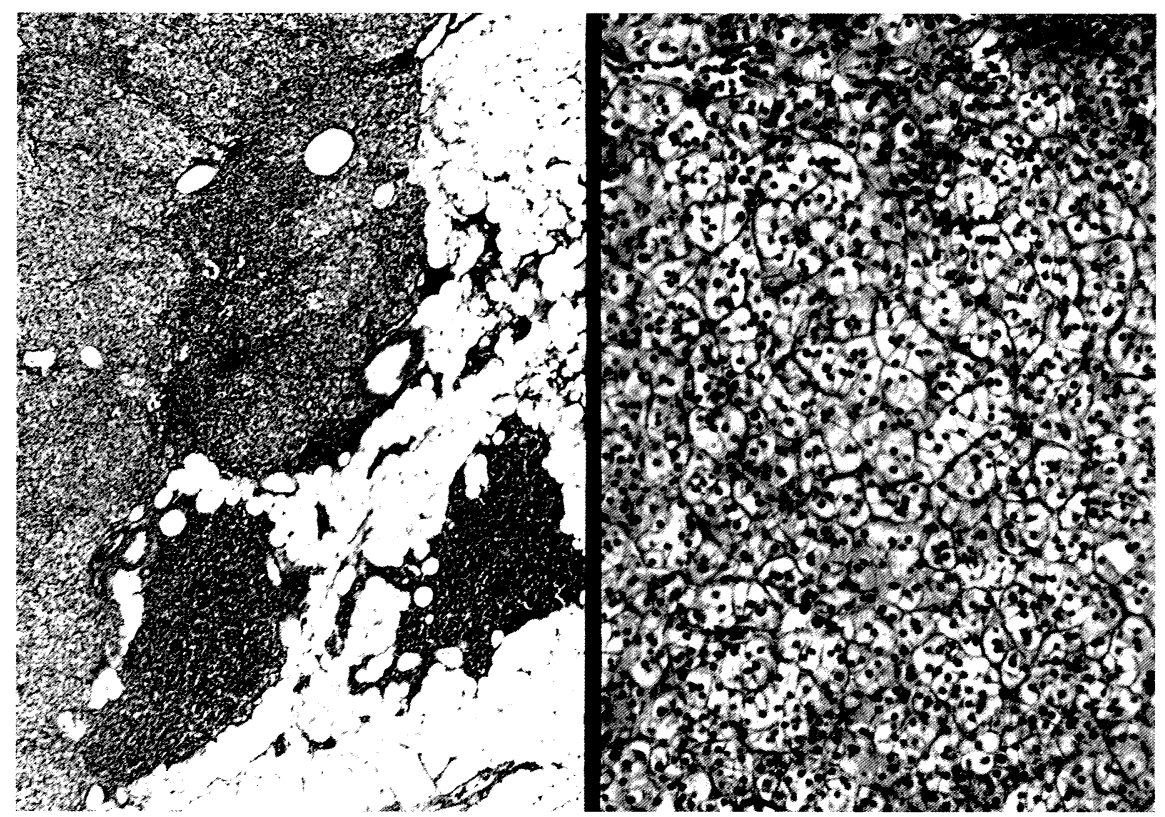

Fig.5 The histological diagnosis of both cases was hyperplasia of the parathyroid (Figure of Case 1. H.E. stain ; original magnification $\times 35$ and $\times 350$ ).

sured $1.4 \times 0.9 \times 0.5 \mathrm{~cm}$ and weighed $1020 \mathrm{mg}$ (Fig.4). The histological diagnosis was hyperplasia of the parathyroid (Fig.5). His serum calcium level resumed the normal level promptly after surgery.

\section{DISCUSSION}

For serching the preoperative localization of hyperfunctioning parathyroid tumor, non-invasive studies such as US, CT, and TTSS are most popular. Furthermore, MRI and selective venous sampling are occasionally performed, but these tests are costly and invasive. More than one of these studies are usually performed before surgery. TTSS is an accepted radionuclide method for imaging abnormal parathyroid tissues, and is particularly useful in searching for ectopic parathyroid glands located around the clavicles or in the mediastinum. However, TTSS is of no use for a small nodule ${ }^{1}$. In Case 1 , the hyperfunctioning parathyroid tissue was in the mediastinum. In Case 2, the size of a resected parathyroid lesion was not so small, however, the lesion was undetectable with TTSS. False-negative results such as both cases are often encountered because of various conditions including not only the size of gland but also the interference of back ground. An improved parathyroid imaging agent had been desired.

A new agent, ${ }^{99 \mathrm{~m}} \mathrm{Tc}-\mathrm{MIBI}$, has been recently reported to be useful for the detection of abnormal parathyroid glands in patients with hyperparathyroidism ${ }^{2 \sim 5}$. ${ }^{99 m}$ Tc-MIBI is a cationic complex introduced for myocardial perfusion imaging as an alternative to
${ }^{201} \mathrm{Tl}$, and was subsequentry applied to parathyroid scintigraphy. We first tried this agent in 1994 for the two cases presented herein, and since then we have used ${ }^{99 \mathrm{~m}} \mathrm{Tc}$-MIBI for the patient with primary or secondary hyperparathyroidism. The diagnostic sensitivity of ${ }^{99 \mathrm{~m}} \mathrm{Tc}-\mathrm{MIBI}$ imaging for hyperfunctioning parathyroid lesions is superior to that of TTSS.

Localization of ${ }^{99 \mathrm{~m}} \mathrm{Tc}-\mathrm{MIBI}$ in the tissue will be dependent not only on the size of the gland but also on blood flow to the tissue, the concentration of ${ }^{99 m} \mathrm{Tc}$ MIBI presented to the tissue, and the binding mechanism in various tissues ${ }^{3}$. Chiu et al. ${ }^{6}$ and Carvalho et al. ${ }^{7)}$ suggested that the tissue with a large number of mitochondria might take up ${ }^{99 \mathrm{~m}} \mathrm{Tc}$-MIBI more avidry than one with less. O'Doherty et al. ${ }^{3)}$ reported that the uptake per gram of parathyroid tissues of ${ }^{99 \mathrm{~m}} \mathrm{Tc}$-MIBI was higher than the uptake per gram of thyroid tissues, but no difference in uptake was observed between ${ }^{201} \mathrm{Tl}$ in these tissues. They reported also that ${ }^{99 \mathrm{~m}} \mathrm{Tc}$-MIBI activity in the parathyroid tissue remained relatively constant following the peak activity, whereas the ${ }^{201} \mathrm{Tl}$ activity steadily declined and activity over the thyroid fell with both tracers, suggesting that the localization would be superior with ${ }^{99 m}$ Tc-MIBI because of the higher target-to-background ratio.

Intraoperative staining using methylene blue is useful to detect abnormal parathyroid glands visually ${ }^{8}$. In our study, all 21 glands with primary hyperparathyroidism were stained with methylene blue. This method is safe and useful for identifing the abnormal gland and discovering the supernumerary glands. 


\section{REFERENCES}

1) Tanaka $Y$, Funahashi H, Imai $T$, et al. Localizing studies in primary hyperparathyroidism (in Japanese). Naibunpitu Geka (Endocrine Surgery) $1994 ; 11: 17-22$.

2) Coakley AJ, Kettle AG, Wells CP, et al. ${ }^{99 \mathrm{~m}}$ Tc-sestamibi - a new agent for parathyroid imaging. Nucl Med Commun 1989; 10 : 791-794.

3) O'Doherty MJ, Kettle AG, Wells P, et al. Parathyroid imaging with technetium-99m-sestamibi : Preoperative localization and tissue uptake studies. J Nucl Med 1992; 33 : 313-318.

4) Weber CJ, Vansant J, Alazraki N, et al. Value of technetium-99m sestamibi iodine 123 imaging in reoperative parathyroid surgery. Surgery 1993; 114: 1011-1018.

5) Katagiri M, Ohtawa $T$, Otsuka N, et al. Detection and localization of enlarged parathyroid glands in patients with hyperparathyroidism using ${ }^{99 \mathrm{~m}} \mathrm{Tc}$ -
Methoxyisobutylisonitrile (MIBI): A study of subtraction scintigraphy with ${ }^{99 m} \mathrm{Tc}$-pertechnetate (in Japanese with English Abst.). Kakuigaku 1995 ; 32 : 465-472.

6) Chiu ML, Kronange JF, Piwnica-Worms D. Effect of mitochondrial and plasma membrane potentials on accumulation of hexakis (2methoxyisobutylisonitrile) technetium (I) in cultured mouse fibroblasts. J Nucl Med 1990; 31 : 1646-1653.

7) Carvalho PA, Chiu ML, Kronauge JF, et al. Subcellular distribution and analysis of technetium-99m-MIBI in isolated perfused rat hearts. J Nucl Med 1992; 33 : 1516-1522.

8) Kobayashi S, Miyakawa M, Sugenoya A, et al. An evaluation of the intraoperative staining technique using methylene blue for the detection of hyperplastic parathyroid glands. Jpn J Surg 1988 ; 18: 729-731. 